\title{
A human-driven decline in global burned area
}

\author{
N. Andela, ${ }^{1,2 *}$ D. C. Morton, ${ }^{1}$ L. Giglio, ${ }^{3}$ Y. Chen, ${ }^{2}$ G. R. van der Werf, ${ }^{4}$ \\ P. S. Kasibhatla, ${ }^{5}$ R. S. DeFries, ${ }^{6}$ G. J. Collatz, ${ }^{1}$ S. Hantson, ${ }^{7}$ S. Kloster, ${ }^{8}$ D. Bachelet, ${ }^{9}$ \\ M. Forrest, ${ }^{10}$ G. Lasslop, ${ }^{8}$ F. Li, ${ }^{11}$ S. Mangeon, ${ }^{12}$ J. R. Melton, ${ }^{13}$ \\ C. Yue, ${ }^{14}$ J. T. Randerson ${ }^{2}$
}

Fire is an essential Earth system process that alters ecosystem and atmospheric composition. Here we assessed long-term fire trends using multiple satellite data sets. We found that global burned area declined by $24.3 \pm 8.8 \%$ over the past 18 years. The estimated decrease in burned area remained robust after adjusting for precipitation variability and was largest in savannas. Agricultural expansion and intensification were primary drivers of declining fire activity. Fewer and smaller fires reduced aerosol concentrations, modified vegetation structure, and increased the magnitude of the terrestrial carbon sink. Fire models were unable to reproduce the pattern and magnitude of observed declines, suggesting that they may overestimate fire emissions in future projections. Using economic and demographic variables, we developed a conceptual model for predicting fire in human-dominated landscapes.

$\mathrm{F}$ ires play an integral role in shaping ecosystem properties (1) and have widespread impacts on climate, biogeochemical cycles, and human health (2-4). Frequent fires are essential for maintaining savanna ecosystems (5), whereas more episodic events in temperate and boreal forests create a mosaic of habitats in different stages of postfire succession (6). Introduction or exclusion of fire from the landscape may lead to rapid shifts in vegetation structure and composition (5), carbon stocks (7), and biodiversity (8). Globally, fire emissions are responsible for 5 to $8 \%$ of the 3.3 million annual premature deaths from poor air quality, and fire is the primary cause of elevated mortality from air pollution across much of the tropics (3). Fires affect global climate through changes in vegetation and soil carbon (7), surface albedo (9), and atmospheric concentrations of aerosols and greenhouse gases (10). Climate feedbacks on fire activity are complex and vary by biome and level of fire suppression (11). Given projected increases in fire risk from climate change (12), fire management will be increasingly important for maintaining ecosystem function, air quality, and other services that influence human wellbeing (13).

Climate is a dominant control on fire activity, regulating vegetation productivity and fuel moisture. Over short time scales, rainfall during the dry season suppresses fire activity, whereas over longer time scales, fuel build-up during wet years in more arid ecosystems can increase burned area in subsequent years (11). The redistribution of precipitation in response to El Niño-Southern Oscillation (ENSO) and other climate modes therefore has a large and sometimes contrasting effect on the interannual variability of biomass burning across continents $(6,14,15)$. Oscillations in Pacific and Atlantic sea surface temperatures also influence trends in fire activity on longer time scales $(6,15)$. Climate change may increase fire risk in many regions $(12,16)$, given projected warming and drying in forests and other biomes with sufficient fuel loads to support fire activity. Ultimately, the interactions among climate, vegetation, and ignition sources determine the spatial and temporal pattern of biomass burning (17).

In addition to natural processes, humans have shaped patterns of global burning for millennia (4), and human activity is now the primary source of ignitions in tropical forests, savannas, and agricultural regions $(14,18)$. Human influence on fire dynamics depends on population density (17), socioeconomic development (19), landscape fragmentation (18), and land management (15), as people introduce or suppress fires (4) and manipulate the timing and fuel conditions of fires in human-dominated landscapes (11, 14). During the past two decades, human population increased by about $25 \%$, or 1.5 billion
(20), and agricultural production increased by more than $40 \%$ (21). Today, about $36 \%$ of the world's land surface is used for pasture or croplands (22), directly affecting the way fire is managed within these ecosystems. Earlier work has demonstrated that cropland expansion or deforestation rates are closely linked to regional fire trends $(14,15)$, and, for many regions, changing fire activity in recent decades extends a longterm transition from natural to human-dominated fire regimes (23-25). However, global implications of changing agricultural management and the mechanisms that regulate fires in human-dominated landscapes remain poorly understood. Even in areas dominated by human sources of ignition, variations in precipitation and other weather conditions may modulate year-to-year variations in ignition efficiency, fire spread rate, and fire size. The interactions among fire weather, fuels, and ignition therefore make it challenging to separate climate and human controls on fire dynamics at regional and global scales. Nevertheless, this separation is necessary to build and improve predictive fire models.

Satellite-derived burned area data provide a consistent global perspective on changing patterns of fire activity. Here, we analyzed long-term trends in burned area from 1998 through 2015 using the Global Fire Emissions Database version 4 product that includes small fires (GFED4s) $(26,27)$. We conducted several analyses to assess the drivers and implications of long-term trends in burned area (28). First, we estimated the influence of precipitation on burned area variability and trends in each $0.25^{\circ}$ grid cell using a statistical model to separate climate and human contributions to fire trends (fig. S1). Second, we separated burned area into contributions from the number and size of individual large fires using 500-m-resolution burned area data from NASA's Moderate Resolution Imaging Spectroradiometer (MODIS) sensors (29) during 2003 to 2015 (fig. S2). Third, we compared observed trends with prognostic fire model estimates from the Fire Model Intercomparison Project (FireMIP), with the aim of understanding limits to fire prediction. Fourth, we examined spatial and temporal relationships between burned area and socioeconomic data to investigate patterns of human influence on fire activity. On the basis of these data, we developed a conceptual model of fire use that considers the roles of land management and socioeconomic development. Finally, we assessed the impact of the observed decreasing burned area trend on ecosystem structure, the magnitude of the terrestrial carbon sink, and atmospheric composition in biomass burning regions. Together, these

\footnotetext{
Biospheric Sciences Laboratory, NASA Goddard Space Flight Center, Greenbelt, MD 20771, USA ²Department of Earth System Science, University of California, Irvine, CA 92697, USA. ${ }^{3}$ Department of Geographical Sciences, University of Maryland, College Park, MD 20742, USA. ${ }^{4}$ Faculty of Earth and Life Sciences, Vrije Universiteit Amsterdam, Amsterdam, Netherlands.

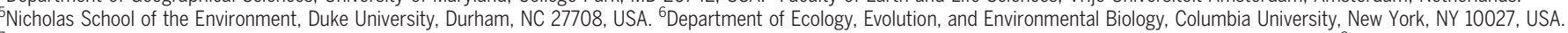

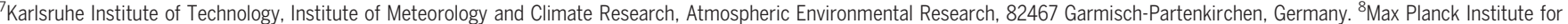

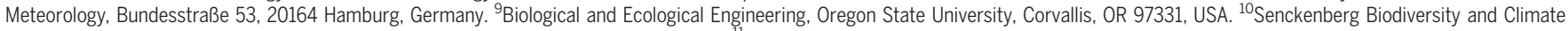

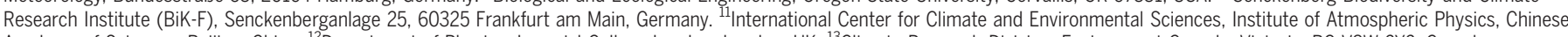
Academy of Sciences, Beijing, China. ${ }^{12}$ Department of Physics, Imperial College London, London, UK. ${ }^{13}$ Climate Research Division, Environment Canada, Victoria, BC V8W 2Y2, Canada. ${ }^{14}$ Laboratoire des Sciences du Climat et de l'Environnement-Institute Pierre Simon Laplace, Commissariat à l'Énergie Atomique et aux Énergies Alternatives (CEA)-Centre National de la Recherche Scientifique (CNRS)-Université de Versailles Saint Quentin, Université Paris-Saclay, 91198 Gif-sur-Yvette, France.

*Corresponding author. Email: niels.andela@nasa.gov
} 
analyses underscore the pervasive influence of human activity on global burned area, including the potential for further declines in savanna fires from ongoing agricultural development across the tropics.

\section{Trends in burned area}

Global burned area declined by nearly onequarter between 1998 and $2015(-24.3 \pm 8.8 \%$, or $-1.35 \pm 0.49 \%$ year $\left.^{-1}\right)$. Large decreases occurred in tropical savannas of South America and Africa and grasslands across the Asian steppe (Fig. 1). Globally, decreases were concentrated in regions with low and intermediate levels of tree cover, whereas an increasing trend was observed in closed-canopy forests. Declining trends were robust when assessed with different burned area data sets and time intervals (Table 1 and fig. S3). Burned area from GFED4s and the 500m MODIS product showed a similar decline during 2003 to $2015\left(-1.28 \pm 0.96 \%\right.$ year $^{-1}$ and $-1.15 \pm 1.21 \%$ year $^{-1}$, respectively), and satellite-based active fire detections from MODIS provided an independent confirmation of the patterns of decreasing global fire activity (fig. S4). Regional increases in burned area were also observed, but areas with a significant decline $(P<0.05)$ in burned area outnumbered areas with a significant increase in burned area for all continents except Eurasia (fig. S5). For tropical savannas and grasslands, declines outnumbered increases by 3:1. Within individual continents, strong contrasting trends were observed between northern and southern Africa, and between Central America and temperate North America (table S1).

Rainfall patterns explained much of the interannual variability in burned area but little of the long-term decline (Table 1 and Fig. 2A). Building on previous work (15), we developed a linear model to adjust for the influence of precipitation variability on burned area (28) (fig. S6). Longterm trends were more significant after reducing precipitation-driven variability. For example, the global decline in burned area of $-1.15 \pm 1.21 \%$ year $^{-1}$ (2003 through 2015, $P<0.1$ ) in the $500 \mathrm{~m}$ MODIS time series strengthened to $-1.23 \pm 0.44 \%$ year $^{-1}(P<0.01)$ after adjusting for precipitation (Table 1). Regionally, precipitation-adjusted burned area time series showed significant declines in Central America, Northern Hemisphere South America, Europe, Northern Hemisphere Africa, and Central Asia (table S1).

A decrease in the number of fires explained most of the global decline in burned area with a smaller contribution from decreasing mean fire size (Fig. 2). The relative contributions from fire number and fire size to observed trends varied considerably among regions (Table 1 and fig. S7). In northern Africa, the number and mean size of fires contributed nearly equally to the net decline in burned area. By contrast, a decrease in the number of fires was the primary factor causing a decline in burned area in South America, Central America, and Central Asia (table S1). Regional and interannual variability in the size distribution of individual fires provided new information about the combined influence of climate, landscape fragmentation, and management on burned area; this information is essential for improving representation of fire in Earth system models.

Current global fire models were unable to predict the magnitude or spatial pattern of the observed decline in global burned area (Fig. 3 and figs. S8 to S10). During 1997 to 2013, FireMIP models $(n=9)$ predicted a mean trend in global burned area of $-0.13 \pm 0.56 \%$ year $^{-1}$, compared to the observed trend of $-1.09 \pm 0.61 \%$ year $^{-1}$ for this interval (28) (Table 1 and table S2). Focusing on the three models that account for human contributions to the number and size of fires (table S3), two models predicted a small decline in global burned area, but often poorly simulated the spatial structure of trends across different continents (Fig. 3 and fig. S8). Despite including
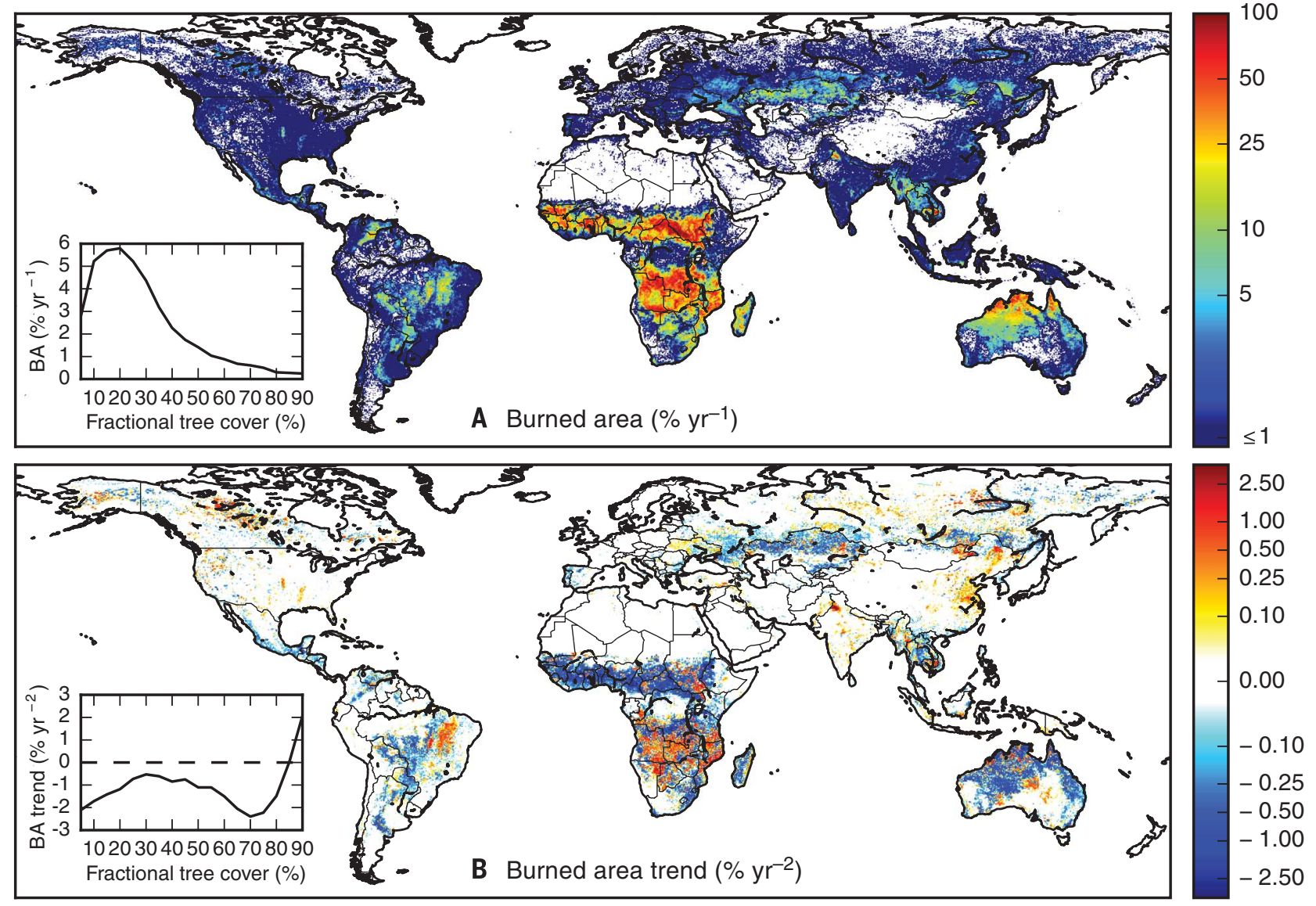

Fig. 1. Satellite observations show a declining trend in fire activity across the world's tropical and temperate grassland ecosystems and land-use frontiers in the Americas and Southeast Asia. (A) mean annual burned area and (B) trends in burned area (GFED4s, 1998 through 2015). Line plots (inset) indicate global burned area and trend distributions by fractional tree cover (28). 
Table 1. Relative trends in burned area, number of fires, and mean fire size for different regions of the world. Trends are shown for different time periods, as indicated, to directly compare burned area estimates from different sources. All trends were calculated by using fire season estimates of burned area, with the exception of the FireMIP data, which were produced per calendar year (28). Increases (regular type) and decreases (bold) in burned area are indicated for each region and time period; significant trends are denoted by asterisks $\left({ }^{*} P<0.1,{ }^{*} P<0.05\right.$, and $\left.{ }^{* * *} P<0.01\right)$.

\begin{tabular}{|c|c|c|c|c|c|c|c|c|c|}
\hline \multirow[b]{2}{*}{ Fire product } & \multirow{2}{*}{$\begin{array}{l}\text { Time } \\
\text { period }\end{array}$} & \multirow{2}{*}{$\begin{array}{l}\text { Full or } \\
\text { residual* }\end{array}$} & \multicolumn{7}{|c|}{ Trend $\left(\%\right.$ year $\left.^{-1}\right)$ with $95 \%$ confidence limits } \\
\hline & & & World & $\begin{array}{c}\text { North } \\
\text { America }\end{array}$ & $\begin{array}{c}\text { South } \\
\text { America }\end{array}$ & Eurasia $^{\dagger}$ & $\begin{array}{c}\text { Southeast } \\
\text { Asia }\end{array}$ & Africa & Australia \\
\hline \multirow{2}{*}{$\begin{array}{r}\text { Burned area } \\
(\text { GFED4s) }\end{array}$} & \multirow{2}{*}{ 1998-2015 } & Full & $-1.35(0.49)^{* * *}$ & $-0.37(2.66)$ & $-1.68(2.75)$ & $-0.80(1.98)$ & $0.23(1.94)$ & $-1.27(0.32)^{* * *}$ & $-2.53(4.23)$ \\
\hline & & PA & $-0.99(0.29)^{* * *}$ & $0.40(2.13)$ & $-0.51(1.68)$ & $-0.26(1.34)$ & $0.25(1.32)$ & $-1.26(0.25)^{* * *}$ & $-0.67(1.91)$ \\
\hline \multirow{2}{*}{$\begin{array}{l}\text { Burned area } \\
\text { (GFED4s) } \\
\text { during the } \\
\text { MODIS era }\end{array}$} & \multirow[b]{2}{*}{ 2003-2015 } & Full & $-1.27(0.95)^{* *}$ & $-0.08(2.17)$ & $-2.66(5.38)$ & $-2.18(2.98)$ & $-0.30(3.23)$ & $-1.51(0.51)^{* * *}$ & $1.48(7.95)$ \\
\hline & & PA & $-1.17(0.39)^{* * *}$ & $0.33(1.77)$ & $-1.75(3.14)$ & $-1.24(1.96)$ & $-0.13(2.02)$ & $-1.45(0.42)^{* * *}$ & * $0.39(3.16)$ \\
\hline \multirow{2}{*}{$\begin{array}{l}\text { Burned area from } \\
500 \mathrm{~m} \text { MODIS } \\
\text { MCD64A1 }\end{array}$} & \multirow[b]{2}{*}{ 2003-2015 } & Full & $-1.15(1.21)^{*}$ & $0.61(2.76)$ & $-1.40(6.99)$ & $-2.23(4.13)$ & $-0.62(3.92)$ & $-1.60(0.56)^{* * *}$ & ${ }^{*} 1.53(8.21)$ \\
\hline & & PA & $-1.23(0.44)^{* * *}$ & $0.78(2.12)$ & $-1.09(3.64)$ & $-1.02(2.35)$ & $-0.61(2.46)$ & $-1.68(0.46)^{* * *}$ & * $0.56(3.40)$ \\
\hline \multirow{2}{*}{ Fire number } & \multirow{2}{*}{ 2003-2015 } & Full & $-0.98(0.73)^{* *}$ & $-1.44(2.92)$ & $-2.67(4.98)$ & $-3.56(4.39)$ & $-1.10(3.36)$ & $-0.87(0.38)^{* * *}$ & $1.50(6.59)$ \\
\hline & & PA & $-1.00(0.35)^{* * *}$ & $-1.41(2.37)$ & $-2.13(2.55)^{*}$ & $-3.46(3.06)^{* *}$ & $-1.03(1.96)$ & $-0.88(0.30)^{* * *}$ & * $0.73(2.83)$ \\
\hline \multirow{2}{*}{ Fire size } & \multirow{2}{*}{ 2003-2015 } & Full & $-0.39(0.38)^{* *}$ & $0.47(1.73)$ & $1.39(2.32)$ & $-0.09(2.03)$ & $-0.68(0.99)$ & $-0.78(0.29)^{* * *}$ & $-0.29(1.69)$ \\
\hline & & PA & $-0.43(0.18)^{* * *}$ & $0.32(1.28)$ & $1.29(1.28)^{* *}$ & $-0.16(1.36)$ & $-0.69(0.85)$ & $-0.81(0.21)^{* * *}$ & $0.08(1.11)$ \\
\hline $\begin{array}{l}\text { 3urned area } \\
\text { predicted } \\
\text { by FireMIP }\end{array}$ & 1997-2013 & Full & $-0.13(0.56)$ & $-0.36(1.37)$ & $-0.06(0.77)$ & $0.06(0.53)$ & $-1.89(1.95)$ & $-0.25(0.70)$ & $-0.50(2.42)$ \\
\hline
\end{tabular}

*Residual time series, after adjusting for the influence of precipitation variability (PA), were estimated by using the approach described in the supplementary materials. tEurasia excludes regions in Southeast Asia. different FireMIP models $(n=9)$ fln this instance, numbers in parentheses are the standard deviation of the trend averaged across the

land use and population as input variables, several models predicted increasing burned area (28) (table S4), consistent with global trends in fire weather (16). These model-data differences highlight the importance of human activity in reducing burning despite growing climate-driven fire risk.

\section{Humans as a driver of the long-term trend}

Population, cropland area, and livestock density were important factors constraining landscape patterns of burning, yet the sign and magnitude of the spatial correlation coefficient between these variables and burned area varied across biomes and along gradients of tree cover (Fig. 4). All three indicators had negative spatial correlations with burned area in savannas and grasslands. Although these three variables had similar global structure, we found that the distribution of agricultural activity clearly modified burned area beyond population alone. For example, widespread agricultural waste burning in large parts of Asia generated a strong positive correlation between cropland and burned area. Similarly, livestock density and burned area were negatively correlated in the Brazilian Cerrado, as livestock may directly suppress fire activity by reducing fuel loads or altering fire management decisions. In tropical forests, population density and cropland were positively correlated with the spatial pattern of burned area, as humans have introduced fires for deforestation and agricultural management $(7,27)$. In boreal forests, we found a stron- ger positive relationship between population and burned area in Eurasia than North America, consistent with past work documenting high levels of human-driven fire activity in Russia (30). Trends in agricultural production and fire activity were also consistent at the national scale. The largest relative declines in GFED4s burned area occurred in countries with the largest increases in agricultural extent and production value (fig. S11).

We developed a conceptual model of changes in burned area with increasing development based on spatial patterns of burned area, land use, population density, and gross domestic product (GDP) data (Fig. 5). Our analysis showed that the evolution of human-dominated fire regimes follows predictable patterns, with the transition from natural to managed landscapes in forest and savanna regions generating markedly different burned area trajectories (28) (figs. S12 and S13). For humid tropical forests, frequent fires for deforestation and agricultural management yielded a sharp rise in fire activity with the expansion of settled land uses, providing quantitative evidence for rapid ecosystem transformation during early land-use transitions described in previous work $(31,32)$. However, in semi-arid savannas and grasslands, the transition from natural landscapes with common land ownership to agriculture on private lands generated a nonlinear decrease in fire activity, even in areas without large-scale land cover conversion. The reorganization of land cover and fire use on the landscape also altered the contributions from different fire types to total burned area (Fig. 5). For both forested and savanna regions, the most rapid changes in both land cover and total burned area occurred for transitions at very low levels of per capita GDP $\left(<\$ 5000 \mathrm{~km}^{-2}\right.$ year $^{-1}$, figs. S12 and S13).

With an expanding human presence on the landscape, increasing investment in agricultural areas reduced fire activity in both savannas and forests (Fig. 5). In highly capitalized regions, burned area was considerably lower, likely as a consequence of both mechanized (fire-free) management and fire suppression to protect highvalue crops, livestock, homes, infrastructure, and air quality (13) (Figs. 4 and 5 and fig. S11). Livelihoods change drastically along this trajectory of fire use, as does the perception of fire and smoke (23). Regulation to improve air quality has significantly reduced cropland burning in the western United States (33). By contrast, fire activity increased in some densely populated agricultural regions of India and China (Figs. 1 and 4), suggesting that without investments in air quality management, agricultural intensification may increase fire activity in regions where crop residue burning is the dominant fire type. Agricultural expansion and intensification are likely to continue in coming decades (21), with the largest changes expected in the tropics, as development shifts vast areas of common land or extensive land uses toward more capital-intensive agricultural production for regional or global markets $(21,32)$. These changes in land use suggest that 
Fig. 2. A decrease in the number of fires was the primary driver of the global decline in burned area. Normalized variation $(2003=1)$ and linear trends in (A) burned area,

(B) number of fires, and (C) mean fire size derived from the MODIS $500 \mathrm{~m}$ product (MCD64A1). Shading denotes 95\% prediction intervals. Adjusting for precipitation-driven trends in burned area isolated residual trends associated with other factors, including human activity (28). (D) Summary of trends in global burned area, calculated as the product of the number and size of fires, after adjusting for the influence of precipitation. Regional trends in fire number and fire size are provided in Table 1 , table S1, and fig. S7.

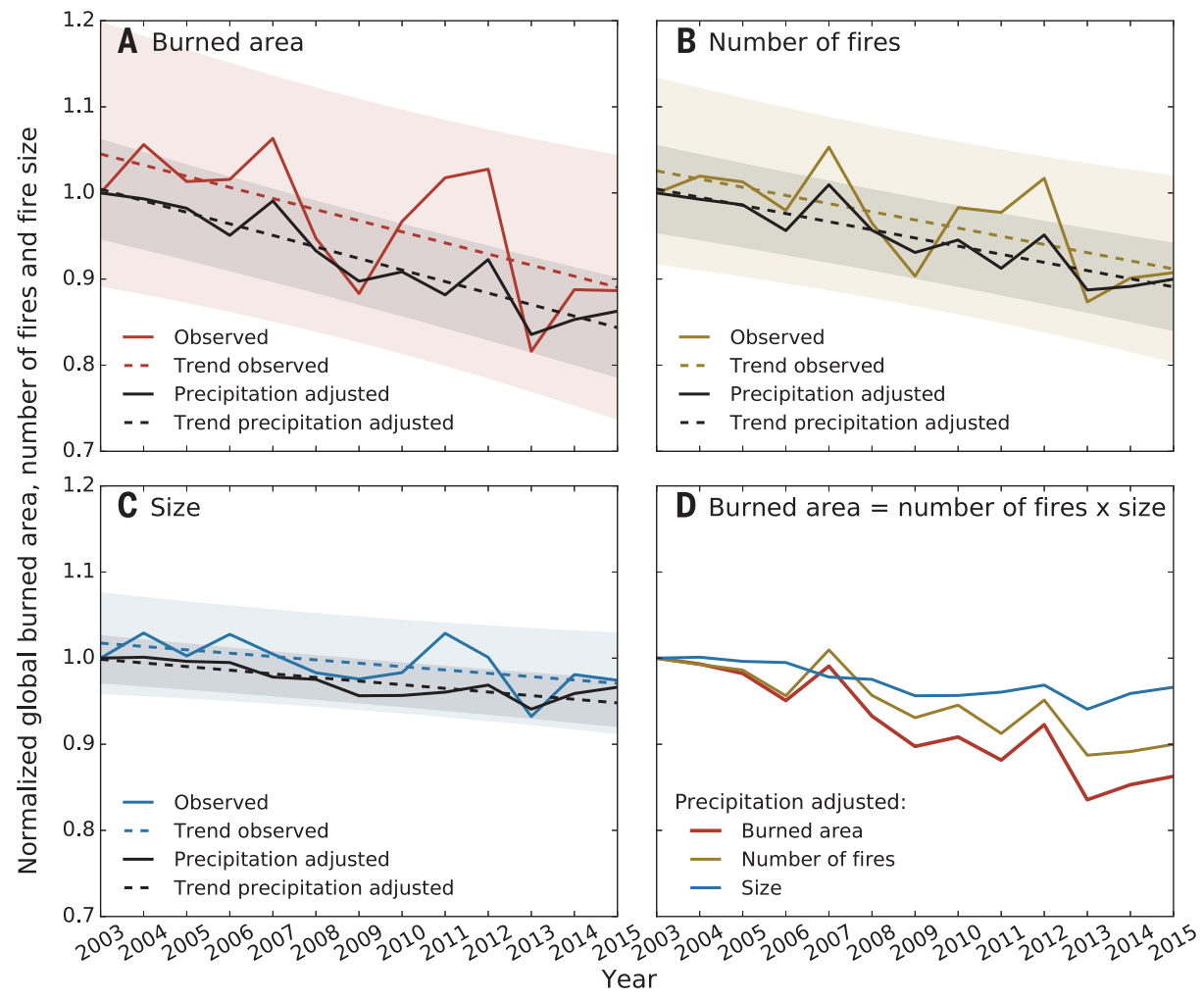

Fig. 3. Comparison of burned area trends from satellite observations (GFED4s) and prognostic fire models from FireMIP. (A) Time series of global burned area. (B) A comparison of global mean annual burned area versus the relative trend in global mean burned area from the observations and models. GFED4s observations are shown in black and FireMIP models are shown with different colors. FireMIP model estimates were available from 1997 through 2013 for six models, from 1997 through 2012 for the CTEM fire module and JULES-INFERNO, and from 1997 through 2009 for MC-Fire. The FireMIP models are described in more detail in the supplementary materials and by Rabin et al. (34) (tables S3 and S4 and fig. S8).
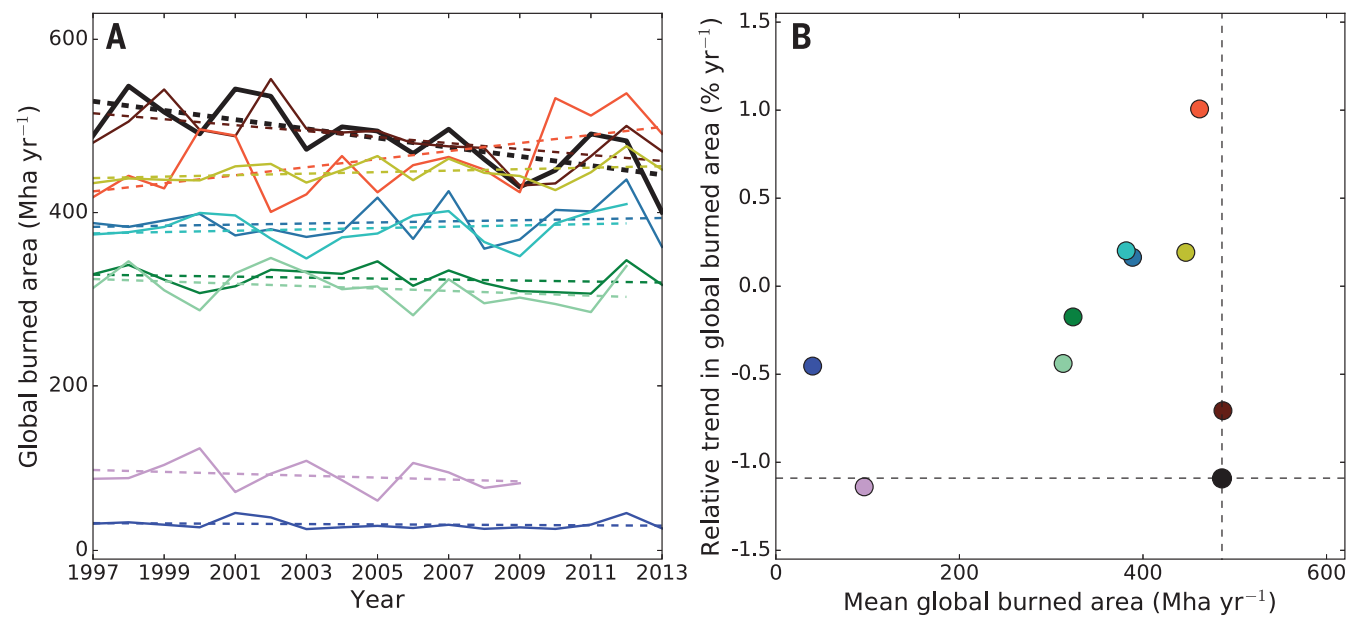

GFED4s

LPJ-GUESS-SIMFIRE-BLAZE

LPJ-GUESS-SPITFIRE $\bigcirc$ JSBACH-SPITFIRE $\bigcirc$ CTEM fire module CLM fire module LPJ-GUESS-GlobFIRM observed declines in burned area may continue or even accelerate in coming decades.

Successful prediction of fire trends on decadal time scales requires a mechanistic description of fire use during the different phases of development shown in Fig. 5. Considering the observational constraints described here, we identified three primary reasons why the FireMIP models were unable to reproduce the observed decline in global burned area. First, all FireMIP models underestimated the magnitude of burned area declines in areas with moderate and high den- sities of population and per capita GDP (fig. S14), suggesting that the models were not sensitive enough to the influence of economic development on fire activity. Second, although many of the FireMIP models included pasture area as a variable describing human modification of land cover, burning in pasture areas was often treated the same as burning in grasslands (table S3), and in many tropical countries, most land areas available for grazing had been converted to pasture by the 1970s. The relative saturation of changing pasture area during the past two decades con- trasted sharply with very large increases in livestock density (fig. S15), highlighting the importance of better integrating drivers of land-use intensification within prognostic models. Third, fire models overestimated burned area in semi-arid tropical ecosystems and underestimated burned area in mesic and humid tropical ecosystems (fig. S14). This bias in the spatial distribution of burned area may have weakened the models' overall sensitivity to human development drivers, because population and wealth changes were more pronounced in areas with higher levels of 

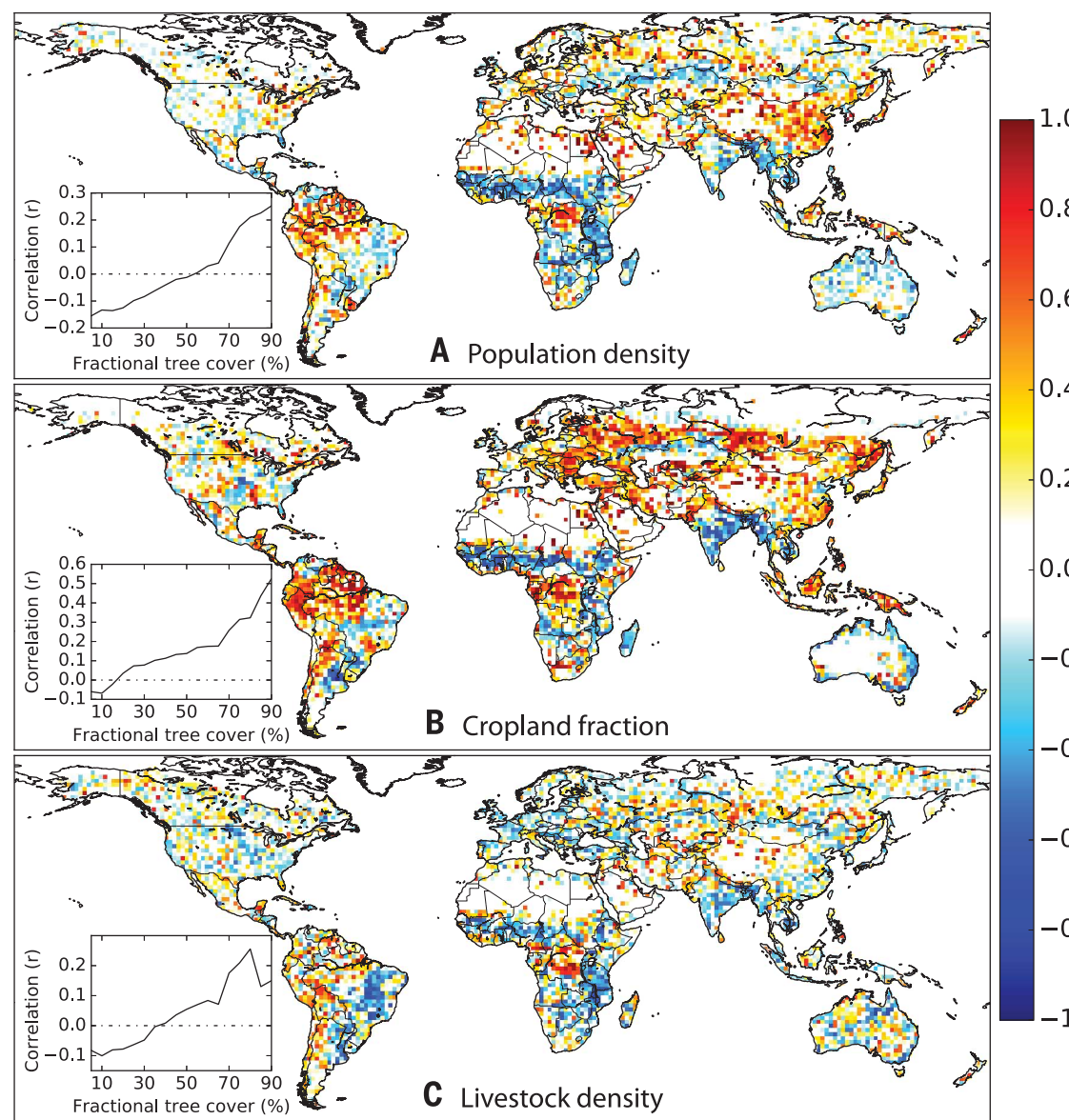

$\rightarrow$
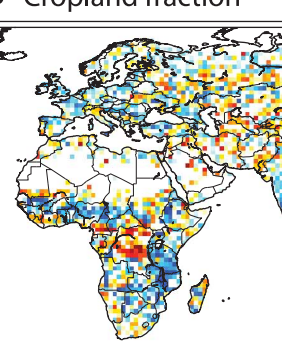

C Livestock density

Fig. 4. Population and agriculture influence the spatial pattern of burned area, with contrasting impacts in different biomes. Maps of the spatial correlation between burned area and

(A) population density per $\mathrm{km}^{2}$, (B) fractional cropland area, and (C) livestock density per $\mathrm{km}^{2}$ Map panels indicate the spatial correlation between burned area (GFED4s) and human land use for the $360.25^{\circ}$ pixels within each $1.5^{\circ}$ grid cell. Line plots (inset) show the mean correlation as a function of fractional tree cover (28)

rainfall. Whereas the spatial pattern of burned area has been widely used as a target for fire model development in past work (34) (fig. S9), our analysis highlights the importance of using trend and fire size observations to constrain scenarios of future fire activity (fig. S10 and table S5).

\section{Implications of declining global fire activity}

The observed large-scale decline of burned area in the world's grasslands, savannas, and tropical land-use frontiers had broad consequences for vegetation dynamics, carbon cycling, air quality, and biodiversity. Fires play an important role in regulating the competition between herbaceous and woody vegetation (5). In grid cells where burned area was equal to or exceeded $10 \%$ year $^{-1}$, we found that the spatial pattern of trends in both dry season enhanced vegetation index (EVI) and vegetation optical depth (VOD) was negatively correlated with trends in burned area, consistent with woody encroachment in areas with declining burned area (28) (table
S6 and fig. S16). However, further analysis of higher-resolution satellite imagery is necessary to quantify the magnitude of encroachment in areas with observed fire trends, as well as other mechanisms that may influence vegetation indices.

Less-frequent burning also allowed biomass, litter, and soil organic matter stocks to accumulate, contributing to a $0.2 \mathrm{Pg}_{\text {year }}{ }^{-1}$ carbon sink by 2015 in tropical and temperate savannas and grasslands (28) (fig. S17, $40^{\circ} \mathrm{N}$ to $40^{\circ} \mathrm{S}$ ). Placing this estimate in the context of the global carbon cycle, declining savanna and grassland fires accounted for about $7 \%$ of the contemporary global net land flux (35) and were likely an important driver of the large and variable terrestrial carbon sink previously reported in semi-arid ecosystems (36). Our estimate of the fire contribution to the terrestrial carbon sink is likely conservative because the biogeochemical model we used did not account for burned area changes prior to 2001, declining emissions in deforestation zones, or woody encroachment in regions with declining fire frequency $(27,28)$.
Analysis of satellite observations of aerosol and carbon monoxide concentrations provided independent evidence of declining fire emissions. Declining fire emissions lowered aerosol concentrations in the major tropical biomass burning regions during the fire season (fig. S4b), leading to improved air quality and regional changes in radiative forcing and atmospheric composition. Although atmospheric transport distributes fire emissions across large areas, we identified a strong local effect of declining burned area on aerosol absorption optical depth in frequently burning grid cells (correlation coefficient $r=0.26, P<0.01$, table S6). Similarly, declining fire activity also lowered regional carbon monoxide concentrations ( $r=0.11, P<0.01$, fig. S4c), suggesting that decreasing biomass burning emissions may have partly offset other drivers of increasing atmospheric methane (37).

Declining fire frequency supports climate mitigation efforts but may run counter to conservation objectives in fire-dependent ecosystems. Frequent fires are a key aspect of many ancient grassland ecosystems that support a range of endemic species (38) and a large portion of the world's remaining wild large mammals (39). The magnitude of habitat and biodiversity losses from declining burned area in savanna and grassland ecosystems may equal or exceed other human impacts in the tropics (Fig. 1), but these impacts have been largely neglected by the international community (40). Challenges for conserving savanna ecosystems abound; trade-offs among conservation, climate mitigation, human health, and agricultural production will ultimately determine the balance of fire activity in savannas and grasslands (Figs. 4 and 5 and figs. S4, S16, and S17).

The strong and sustained burned area declines in grasslands and savannas documented here represent a first-order impact on the Earth system, with consequences for ecosystems and climate that may be comparable with those of other large-scale drivers of global change. A shift toward more capital-intensive agriculture has led to fewer and smaller fires, driven by population increases, socioeconomic development, and demand for agricultural products from regional and global markets. Together, these factors influence fire use in predictable ways, with a strong inverse relationship between burned area and economic development (Fig. 5). The pervasive influence of human activity on burned area was not captured by state-of-the-art fire models; improving these models in the future may require a more sophisticated representation of land-use intensification and its influence on fire dynamics. Despite potential increasing fire risk from climate change $(12,16)$, ongoing socioeconomic development will likely sustain observed declines in fire in savanna and grassland ecosystems in coming decades, altering vegetation structure and biodiversity. Fire is one of the oldest tools for human landscape management, yet the use of fire is rapidly changing in response to the expansion of global agriculture. Achieving a balance between conservation of firedependent ecosystems and increasing agricultural production to support growing populations 

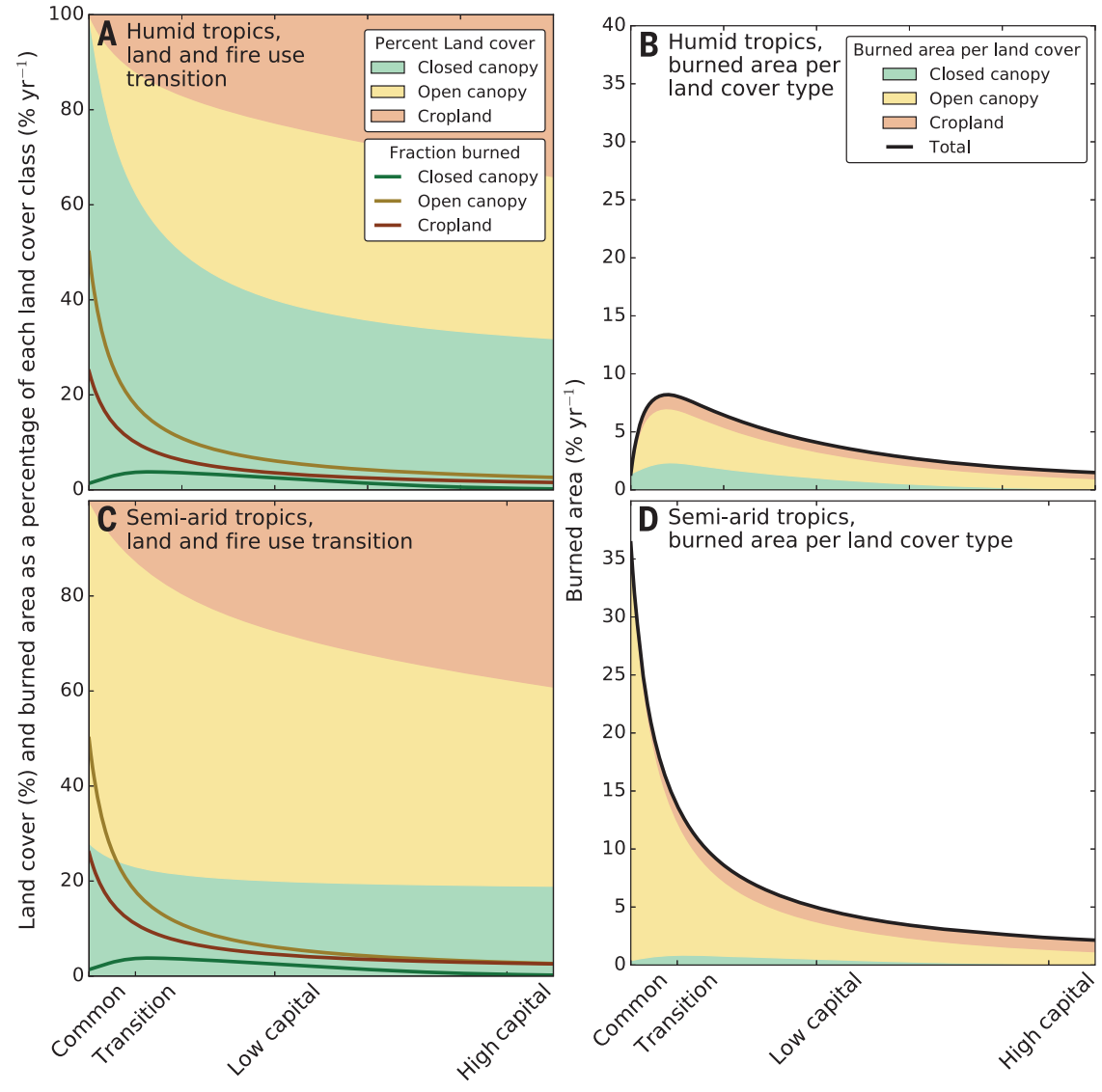

Fig. 5. Conceptual model showing changes in fire use along the continuum from common land ownership to highly capitalized agricultural management on private lands. In humid tropical regions (A and B) (precipitation $\geq 1200 \mathrm{~mm}$ year ${ }^{-1}$ ), deforestation fires for agricultural expansion (A) lead to peak burned area during an early land-use transition phase to more settled land uses (B). In the semi-arid tropics (C and D) (precipitation 500 to $1200 \mathrm{~mm}_{\text {year }}{ }^{-1}$ ), burned area is highest under common land ownership (D), as intact savanna and grazing lands allow for the spread of large fires. Conversion of savanna and grassland systems for more permanent agriculture (C) drives a nonlinear decline in burned area from landscape fragmentation and changing fire use for agricultural management (D). The conceptual model is based on the spatial distribution of burned area, land use, population, and GDP (28) (figs. S12 and S13). Similar patterns are observed across all continents, but absolute burned area differs as a function of culture, climate, and vegetation.

will require careful management of fire activity in human-dominated landscapes.

\section{REFERENCES AND NOTES}

1. W. J. Bond, F. I. Woodward, G. F. Midgley, New Phytol. 165 525-538 (2005)

2. P. J. Crutzen, M. O. Andreae, Science 250, 1669-1678 (1990).

3. J. Lelieveld, J. S. Evans, M. Fnais, D. Giannadaki, A. Pozzer, Nature 525, 367-371 (2015).

4. D. M. J. S. Bowman et al., Science 324, 481-484 (2009).

5. R. J. Scholes, S. R. Archer, Annu. Rev. Ecol. Syst. 28, 517-544 (1997).

6. T. W. Swetnam, J. L. Betancourt, Science 249, 1017-1020 (1990).
S. E. Page et al., Nature 420, 61-65 (2002)

8. M. A. Cochrane, M. D. Schulze, Biotropica 31, 2-16 (1999).

9. J. T. Randerson et al., Science 314, 1130-1132 (2006).

10. D. S. Ward et al., Atmos. Chem. Phys. 12, 10857-10886 (2012).

11. S. Archibald, A. Nickless, N. Govender, R. J. Scholes, V. Lehsten, Glob. Ecol. Biogeogr. 19, 794-809 (2010).

12. O. Pechony, D. T. Shindell, Proc. Natl. Acad. Sci. U.S.A. 107, 19167-19170 (2010).

13. M. A. Moritz et al., Nature 515, 58-66 (2014)

14. L. E. Aragão et al., Philos. Trans. R. Soc. London B Biol. Sci. 363, 1779-1785 (2008).

15. N. Andela, G. R. van der Werf, Nat. Clim. Chang. 4, 791-795 (2014)

16. W. M. Jolly et al., Nat. Commun. 6, 7537 (2015)
17. I. Bistinas, S. P. Harrison, I. C. Prentice, J. M. C. Pereira, Biogeosciences 11, 5087-5101 (2014).

18. S. Archibald, D. P. Roy, B. W. van Wilgen, R. J. Scholes, Glob. Change Biol. 15, 613-630 (2009).

19. E. Chuvieco, C. O. Justice, in Advances in Earth Observation of Global Change, E. Chuvieco, J. Li, X. Yang, Eds. (2010), pp. 187-199.

20. United States Census Bureau, Historical estimates of world population; www.census.gov.

21. N. Alexandratos, J. Bruinsma, Food and Agriculture Organization, World agriculture towards 2030/2050: The 2012 revision. ESA Work. Pap. No. 12-03 (2012)

22. N. Ramankutty, A. T. Evan, C. Monfreda, J. A. Foley, Global Biogeochem. Cycles 22, GB1003 (2008).

23. S. J. Pyne, Fire in America. A Cultural History of Wildland and Rural Fire (Princeton Univ. Press, 1982)

24. M. J. E. van Marle et al., Historic global biomass burning emissions based on merging satellite observations with proxies and fire models (1750-2015). Geosci. Model Dev. Discuss. (2017). doi: 10.5194/gmd-2017-32.

25. J. R. Marlon et al., Nat. Geosci. 1, 697-702 (2008).

26. J. T. Randerson, Y. Chen, G. R. van der Werf, B. M. Rogers, D. C. Morton, J. Geophys. Res. 117, G04012 (2012).

27. G. R. van der Werf et al., Global fire emissions estimates during 1997-2015. Earth Syst. Sci. Data Discuss. 10.5194/ essd-2016-62 (2017).

28. Materials and methods are available as supplementary materials.

29. L. Giglio, T. Loboda, D. P. Roy, B. Quayle, C. O. Justice, Remote Sens. Environ. 113, 408-420 (2009).

30. D. Mollicone, H. D. Eva, F. Achard, Nature 440, 436-437 (2006).

31. J. A. Foley et al.. Science 309, 570-574 (2005).

32. T. K. Rudel, R. Defries, G. P. Asner, W. F. Laurance, Conserv. Biol. 23, 1396-1405 (2009).

33. H.-W. Lin et al., J. Geophys. Res. Biogeosci. 119, 645-660 (2014)

34. S. S. Rabin et al., Geosci. Model Dev. 10, 1175-1197 (2017).

35. C. Le Quéré et al., Earth Syst. Sci. Data 7, 47-85 (2015).

36. A. Ahlström et al., Science 348, 895-899 (2015)

37. A. L. Rice et al., Proc. Natl. Acad. Sci. U.S.A. 113, 10791-10796 (2016).

38. W. J. Bond, Science 351, 120-122 (2016)

39. G. P. Hempson, S. Archibald, W. J. Bond, Science 350 1056-1061 (2015).

40. C. L. Parr, C. E. R. Lehmann, W. J. Bond, W. A. Hoffmann, A. N. Andersen, Trends Ecol. Evol. 29, 205-213 (2014).

\section{ACKNOWLEDGMENTS}

N.A, Y.C., and J.T.R. received funding from the Gordon and Betty Moore Foundation (grant GBMF3269). D.C.M. was supported by NASA's Interdisciplinary Science and Carbon Monitoring System Programs. G.R.v.d.W. was supported by the Netherlands Organisation for Scientific Research (NWO), S.H. by the EU FP7 projects BACCHUS (grant 603445) and LUC4C (grant 603542), F.L. by the National Science Foundation of China (grant 41475099), and C.Y. by the European Space Agency Fire_CCI project. We thank M. N. Deeter for helpful suggestions on the $\mathrm{CO}$ analysis. The authors declare that they have no competing interests. Data used in this study are available at www.globalfiredata.org, https://reverb.echo.nasa.gov/, http://gpcp. umd.edu/, www.fao.org, and http://web.ornl.gov/sci/landscan/ and are described in more detail in the supplementary materials. FireMIP model simulation output is archived with the supporting information, and full data sets are available on request.

\section{SUPPLEMENTARY MATERIALS}

www.sciencemag.org/content/356/6345/1356/suppl/DC1 Materials and Methods

Figs. S1 to S18

Tables S1 to S6

References (41-90)

22 November 2016; accepted 2 June 2017

10.1126/science.aal4108 


\section{Science}

\section{A human-driven decline in global burned area}

N. Andela, D. C. Morton, L. Giglio, Y. Chen, G. R. van der Werf, P. S. Kasibhatla, R. S. DeFries, G. J. Collatz, S. Hantson, S. Kloster, D. Bachelet, M. Forrest, G. Lasslop, F. Li, S. Mangeon, J. R. Melton, C. Yue and J. T. Randerson

Science 356 (6345), 1356-1362.

DOI: $10.1126 /$ science.aal4108

\section{Burn less, baby, burn less}

Humans have, and always have had, a major impact on wildfire activity, which is expected to increase in our warming world. Andela et al. use satellite data to show that, unexpectedly, global burned area declined by $\sim 25 \%$ over the past 18 years, despite the influence of climate. The decrease has been largest in savannas and grasslands because of agricultural expansion and intensification. The decline of burned area has consequences for predictions of future changes to the atmosphere, vegetation, and the terrestrial carbon sink.

Science, this issue p. 1356

ARTICLE TOOLS

SUPPLEMENTARY MATERIALS

REFERENCES

PERMISSIONS http://science.sciencemag.org/content/356/6345/1356

http://science.sciencemag.org/content/suppl/2017/06/28/356.6345.1356.DC1

This article cites 80 articles, 14 of which you can access for free http://science.sciencemag.org/content/356/6345/1356\#BIBL

http://www.sciencemag.org/help/reprints-and-permissions

Use of this article is subject to the Terms of Service

Science (print ISSN 0036-8075; online ISSN 1095-9203) is published by the American Association for the Advancement of Science, 1200 New York Avenue NW, Washington, DC 20005. The title Science is a registered trademark of AAAS.

Copyright @ 2017 The Authors, some rights reserved; exclusive licensee American Association for the Advancement of Science. No claim to original U.S. Government Works 